TAO, Vol. 16, No. 4, 763-774, October 2005

\title{
Soil Gas Radon Spectra and Earthquakes
}

\author{
L. Lynn Chyi ${ }^{1, *}$, Thomas J. Quick ${ }^{1}$, Tsanyao Frank Yang ${ }^{2}$, and Cheng-Hong Chen ${ }^{2}$
}

(Manuscript received 3 May 2004, in final form 20 July 2005)

\begin{abstract}
Continuous soil gas radon monitoring in real time with improved solidstate detector is carried out in south-central and southern Taiwan. The time series register spike-like anomalies which could be precursors of earthquakes. Monitoring stations located in a brecciated zone of active fault at Taiwan 3 and faults at Taiwan 1 showed drastic variations of radon when the terrain is stressed before the onset of earthquake. In contrast, the spectrum recorded at a station sited on a craton Akron 1 which is sited on a craton shows no significant radon variations. To actually prove that the variation of the time series is related to stress, a fourth station was anchored in a sand column $(209 \mathrm{~L})$ with exactly the same type of radon detector system. The time series recorded in this manner shows higher background level and spikes of high radon counts as it is stressed. Temperature and moisture variations are not affecting radon counts.
\end{abstract}

(Key words: Earthquake, Tectonic stress, Precursor, Radon spikes, Taiwan)

\section{INTRODUCTION}

Ulomov and Mavashev (1967) reported the increase of radon level in deep wells in Uzbekstan before the onset of major earthquakes more then thirty years ago. Since then using radon level for short term earthquake prediction is carried out all over the world (e.g., Walia et al. 2005; Yang et al. 2005). Toutain and Baubron (1998) summarized the publications on soil and spring gases with respect to seismotectonics showing relationships between radon anomalies and earthquakes. Zmazek et al. (2005) described how anomalies preceding an earthquake on a radon time series recorded in boreholes could be identified.

\footnotetext{
1 Department of Geology, University of Akron, Akron, OH 44325-4101, USA

2 Department of Geosciences, National Taiwan University, Taipei, Taiwan, ROC

* Corresponding author address: Dr. L. Lynn Chyi, Department of Geology, University of Akron, Akron, $\mathrm{OH}$ 44325-4101, USA; E-mail: LChyi@UAkron.edu
} 
The aim of the present paper is to show how field-monitoring results are correlated to laboratory monitoring results under known conditions. Through continuing experiments under known conditions, we could gain insight into what could have happened in nature. Eventually make earthquake prediction using continuous radon monitoring a meaningful technique in predicting earthquake.

Taiwan is located at the junction of the Ryukyu and the Philippine arc. The intense interaction of the Eurasia and Philippine Sea plate made a small portion of the latter obducted on the former in eastern Taiwan. Taiwan has two tectonic movements; one is the obduction of the Philippine Sea plate northwestward against the Eurasia Plate and the other one is the movement of the Philippine Sea Plate northward toward the Okinawa trench. Most of the earthquakes in Taiwan are related to these two movements as well as the distribution of major faults (Lin et al. 2000) (Fig. 1). The Chisan fault, where Taiwan 3 is located, is considered an active fault recently rather than a suspected one earlier (Sung et al. 2004).

As a real rock mass is responding to a continuous stress, there could be elastic compression, plastic flow, and brittle failure (Morgounov 2001). The major process induces earthquake in the hillside of southwestern Taiwan is probably dominated by brittle failure. As reported by Suppe (1983), shallow depth thin-layered fault-bend folding is the principal type of deformation in southwestern Taiwan. In this case, the fracture process becomes more predictable. When InSAR images released by European Space Agency (2003) are examined, fringes are found to cover a wide area near the West coast, and areas in the Northeast and Eastern coastal plains. The stress in these areas is probably partially absorbed by plastic flow of surface sediments. The flying start and then a slow slip as described by Bilham (2005) could justify such kind of deformation.

Perceivable earthquake occurs in Taiwan almost every day. Therefore, it is difficult to say whether the prediction of these earthquakes really have any merit. However, if we look at damaging earthquakes with $\mathrm{M}_{\mathrm{L}}>7.0$ (magnitude in Richter scale) for the last 100 years, either measured or estimated by Central Weather Bureau of Taiwan, then it has a probability of occurring every ten years. It makes sense then if the emphasis of earthquake prediction is aimed at earthquakes with this magnitude or larger.

\section{FIELD METHODOLOGY}

Field monitoring station has a protected detector assembly and a constructed radon-receiving zone. Chyi et al. $(2001 ; 2002 a)$ discussed the details of the construction of the monitoring site. The detector assembly has three parts, a silicon photodiode radon detector, an interface, and a data logger. The data could be logged directly onto the memory system of a computer. The detector assembly is enclosed in a PVC pipe housing to reduce the influence of environmental factors such as temperature, air pressure, wind, and moisture. The pipe housing is buried in a ditch lined with gravel and covered with a liner to homogenize and amplify the radon reception. The ditch drains well to prevent water logging during typhoon season. It is built in a proven active fault zone so the terrain is responsive to the accumulation of stress. The radon time series recording at Taiwan 1 (Fig. 1) is continuous from the end of October 2000 
through May 2003. However, moisture condensation during warmer months May through October, the recordings are not reliable and this excluded from the presentation.

A thermometer and a hygrometer were placed side by side with the radon counting system at Akron 1 to indicate contemporaneous temperature and relative humidity changes. It is placed outside our laboratory at the University of Akron to observe how soil gas radon varies over a craton. To observe the variation of spectrum or time series related to stress, Akron 2 is anchored in a sand column prepared inside a $(209 \mathrm{~L})$ drum (Fig. 2). The radon detector system is

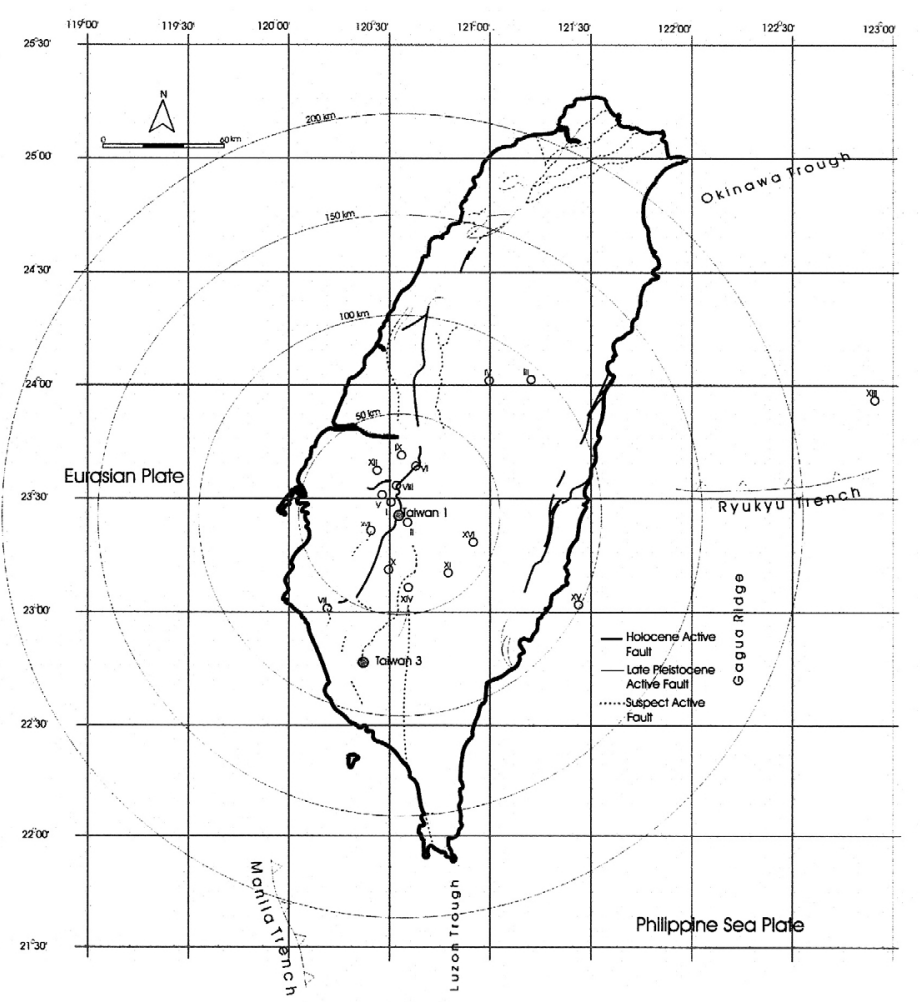

Fig. 1. Tectonic units in the vicinity and distribution of major active and inactive faults in Taiwan and location of earthquake detected. The island has a core of igneous and metamorphic area with high geothermal gradient. Major faulting is confined to the wider plain in the west and the narrower coastal valley in the east (modified after Lin et al. 2000). Locations of earthquakes with precursors visible on the spectra recorded are shown in Roman numerals. The four great circles with $50 \mathrm{~km}, 100 \mathrm{~km}, 150 \mathrm{~km}$, and $200 \mathrm{~km}$ marked are epicenter distance references. For the clarity of plotting, nearby earthquakes are identified with the same Roman numerals. Monitoring stations Taiwan 1 and Taiwan 3 are identified with shaded circles. 
identical to that of Akron 1. It is placed in the middle of the sand column to record radon while the system is stressed from the top by weight additions. Glacial sand containing fair amount of shale, chert, granitic, and gneissic particles (Baugues 1993) from a quarry near Akron is used for this column. The entire setup is placed inside a laboratory with small temperature and relative humidity variations.

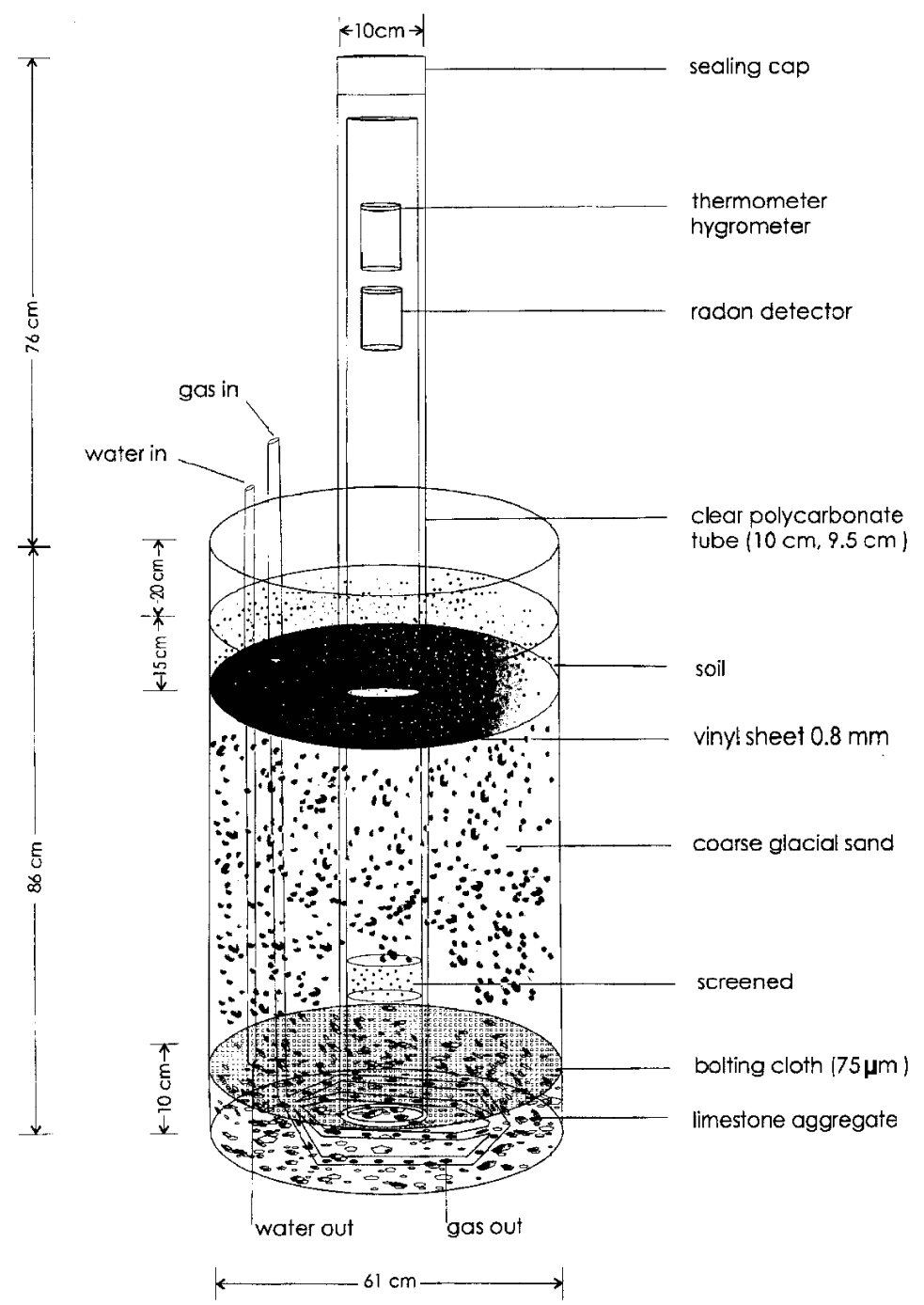

Fig. 2. The construction and other essential dimensions of the experimental drum setup. Water and gas inlets are sealed at present time. The radon level of the glacial sands used in the experiment is higher than that in ordinary soil gas. 


\section{THE MONITORING STATIONS}

Real time monitoring of radon as an earthquake precursor started in Iceland (Hauksson and Goddard 1981) within a fault zone. Their approach was very similar to ours but radon was recorded only once or twice a week. With this long time period, they were incapable of detecting spike-like anomalies lasted only a few hours or shorter. However, our continuous counting with detectors buried in an engineered ditch in active fault zone is a new approach. It appears that in the vicinity of these two monitoring sites, the stress is mainly absorbed in brittle failure or the movements of faults.

Station Taiwan 1 (Fig. 1) is placed within a fault zone at village Chunglun where four active faults come together and form a $200 \mathrm{~m}$ wide brecciate zone. Mud volcanoes are abundant within this fault zone. Water temperature is only slightly above the ambient atmosphere (Jiang 2003) indicating that the source of water is not very deep. Station Taiwan 3 is placed in Yentsao village near Chisan fault (Fig. 1). Mud volcanoes are found on both sides along the fault zone. Radon is exhaling at both sites with different carrier gases (Yang et al. 2003). Taiwan 3 is located on a college campus, became operational in late summer of 2002 but unfortunately the site was troubled with a half an hour power outage each week.

Counting system identical to that at Taiwan was installed on the campus of the University of Akron outside of our laboratory and is designated as Akron 1. The detector system is buried in ditch of similar design. Akron is located on North American craton. Even there are infrequent minor earthquakes, there was no perceivable earthquake struck the area during the past several years.

\section{RESULTS}

Considering the latest observation at Akron 1, it is clear that construction activities nearby, backfilling in particular, are affecting soil gas release and thus radon counting rate. Careful site selection and away from construction or traffic activities is imperative for the placement of monitoring system is imperative to maximize the signal to noise ratio. Radon level at this site is not significantly affected by ambient temperature and relative humidity variations as demonstrated by the spectrum recorded from November 2002, through February 2003 (Fig. 3). There was no discernible spike-like radon anomaly during this period. In addition, temperature varies from over $18^{\circ} \mathrm{C}$ down to $-7^{\circ} \mathrm{C}$ with contemporaneous relative humidity varies between 100 and $25 \%$. With a ground temperature of about $10^{\circ} \mathrm{C}$, a down flux of ambient air is expected through a portion of this period. It is obvious that down flux is not affecting the radon count. The PVC housing as designed appears to be adequate in handing ambient factors affecting soil gas radon variation.

There are 187 perceivable earthquakes for the first eight months of this year as reported by Central Weather Bureau of Taiwan (2003), or 0.6 earthquakes per day. Among these earthquakes only those with $\mathrm{M}_{\mathrm{L}}=4$ or larger are probably detectable on the recorded spectrum. Therefore, radon spectrum recorded in Taiwan is expected to have numerous radon anomalies if the anomalies are indeed related to stress of the terrain. 


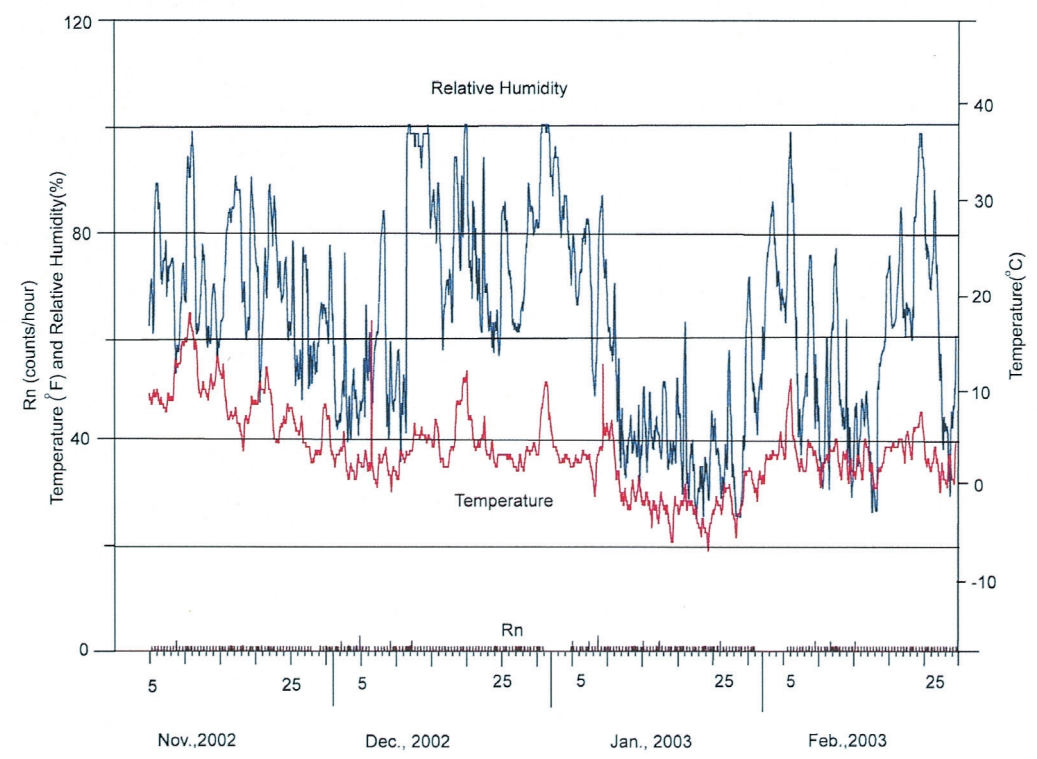

Fig. 3. Radon time series recorded over North American craton at Akron 1.

Radon time series recorded in real time during late 2000 and early 2001 demonstrated that precursors are found between 0.49 to 7.40 days before earthquakes with $\mathrm{M}_{\mathrm{L}}$ from 3.7 to 5.2 and within a $30 \times 100 \mathrm{~km}$ elliptical domain with the long axis following the structure trend of the island but offset by about $20^{\circ}$ to the east (Chyi et al. 2001). The domain is likely to be larger if the magnitude of earthquake becomes larger. Continuing monitoring during the ensuing years showed that precursors for much larger earthquake, $\mathrm{M}_{\mathrm{L}}=6.7$ as listed in Table 1, was also detected at a longer distance of $235 \mathrm{~km}$ (Chyi et al. 2002b) and intervals between the spike-like anomalies and the earthquake could be as long as 13.0 days (Table 1).

The locations of these earthquakes are listed in Table 1 in Roman numerals and their locations are plotted in Fig. 1. Thirty earthquakes occurred around II, VI, IX, X, and XI among a total of 37 radon peaks observed. The magnitudes and time intervals between the spike-like radon signals and the onset of earthquakes at these locations appear to vary within a large range and appear to be random; no clear relationship to depth and magnitude of earthquakes. For instance at location II, only a few km southeast of Taiwan 1, the time interval could vary between 0.59 and 13.0 days, the magnitudes from 4.1 to 4.8 , and the depth from 6.3 to 15.7 $\mathrm{km}$. Precursors 4, 16, 17, and 35 appear to relate to more than one earthquake occurrences. All the spike-like anomalies are found on elevated radon level, which is likely to be related to the stress accumulation. Because ${ }^{222} \mathrm{Rn}$ has a short half-life of 3.825 days and the detector system is monitoring upward radon migration. The spectrum recorded cannot indicate radon migration processes dated more than a few weeks. The time interval of radon anomaly measured in well water, however, could indicate a concentration process lasted a much longer time. 
Table 1. Radon precusor and earthquake characteristics.

\begin{tabular}{|c|c|c|c|c|c|c|c|}
\hline No. & Precursor & Earthquake & Interval(day) & Distance (km) & Depth(km) & Magnitude & Location \\
\hline 01 & $10 / 31 / 001413$ & $11 / 01 / 001708$ & 1.12 & 9.0 & 11.9 & 4.1 & I \\
\hline 02 & $11 / 17 / 001230$ & $11 / 18 / 001621$ & 1.16 & 4.5 & 15.7 & 4.1 & II \\
\hline 03 & $12 / 21 / 000934$ & $12 / 22 / 001922$ & 1.41 & 96.5 & 3.0 & 4.7 & III \\
\hline \multirow[t]{2}{*}{04} & $01 / 10 / 011456$ & $01 / 11 / 011637$ & 1.08 & 88.3 & 24.6 & 5.2 & IV \\
\hline & & $01 / 11 / 011709$ & 1.10 & 89.8 & 25.0 & 5.0 & IV \\
\hline 05 & $01 / 22 / 011235$ & $01 / 28 / 012108$ & 6.36 & 15.7 & 6.3 & 4.5 & V \\
\hline 06 & $01 / 29 / 011400$ & $02 / 02 / 010605$ & 4.16 & 16.2 & 2.1 & 4.3 & V] \\
\hline 07 & $01 / 29 / 011116$ & $02 / 05 / 012048$ & 7.40 & 50.0 & 22.5 & 4.2 & VII \\
\hline 08 & $02 / 01 / 011329$ & $02 / 02 / 010112$ & 0.49 & 22.9 & 11.8 & 3.7 & V \\
\hline 09 & $02 / 03 / 011147$ & $02 / 09 / 010134$ & 5.59 & 9.8 & 7.0 & 4.9 & II \\
\hline 10 & $02 / 03 / 011927$ & $02 / 09 / 010217$ & 5.37 & 8.7 & 11.8 & 4.2 & VIII \\
\hline 11 & $02 / 08 / 011820$ & $02 / 11 / 012043$ & 3.10 & 64.6 & 13.9 & 4.7 & Vl \\
\hline 12 & 02/10/010919 & $02 / 14 / 012117$ & 4.50 & 30.7 & 18.2 & 4.5 & Vl \\
\hline $13 \mathrm{a}$ & $02 / 11 / 011643$ & $02 / 15 / 010625$ & 3.57 & 30.4 & 17.7 & 4.7 & Vl \\
\hline $13 b$ & $02 / 12 / 010919$ & $02 / 15 / 010625$ & 3.75 & 29.8 & 18.1 & 4.3 & VI \\
\hline 14 & $02 / 15 / 011822$ & $02 / 19 / 010425$ & 3.41 & 30.4 & 18.4 & 5.2 & $\mathrm{Vl}$ \\
\hline 15 & $02 / 18 / 011834$ & $02 / 20 / 010941$ & 1.64 & 31.9 & 18.9 & 4.8 & IX \\
\hline \multirow[t]{2}{*}{16} & $03 / 03 / 012303$ & $03 / 06 / 011835$ & 2.81 & 22.5 & 13.5 & 3.9 & XII \\
\hline & & $03 / 08 / 010409$ & 4.21 & 30.4 & 19.6 & 3.9 & IX \\
\hline \multirow[t]{4}{*}{17} & $03 / 09 / 012124$ & $03 / 12 / 010224$ & 2.21 & 31.0 & 17.9 & 4.8 & IX \\
\hline & & $03 / 12 / 010947$ & 2.52 & 29.2 & 15.8 & 4.6 & IX \\
\hline & & $03 / 12 / 011729$ & 2.84 & 26.8 & 18.3 & 4.1 & $x$ \\
\hline & & $03 / 14 / 010654$ & 4.40 & 41.8 & 14.1 & 4.3 & IX \\
\hline 18 & $03 / 26 / 011816$ & & & & & & \\
\hline 19 & $04 / 15 / 010715$ & $04 / 22 / 010252$ & 6.82 & 16.3 & 6.3 & 4.1 & II \\
\hline 20 & $04 / 27 / 012346$ & $04 / 29 / 0 \leq 1437$ & 1.62 & 28.7 & 11.7 & 4.8 & IX \\
\hline 21 & $11 / 29 / 010726$ & $12 / 07 / 011608$ & 8.36 & 39.3 & 3.0 & 4.6 & $\mathrm{XI}$ \\
\hline 22 & $12 / 17 / 010334$ & $12 / 18 / 011203$ & 1.35 & 257.5 & 32.2 & 6.7 & XIII \\
\hline 23 & $01 / 23 / 020448$ & $01 / 24 / 021821$ & 1.56 & 40.3 & 19.5 & 4.1 & XIV \\
\hline 24 & $02 / 16 / 020213$ & $01 / 29 / 021024$ & 3.34 & 112.0 & 11.8 & 5.1 & $X V$ \\
\hline 25 & $02 / 07 / 020349$ & $02 / 12 / 021127$ & 5.31 & 120.3 & 25.1 & 6.2 & XIII \\
\hline 26 & $02 / 27 / 021056$ & $03 / 01 / 021539$ & 2.20 & 41.2 & 3.0 & 4.0 & XI \\
\hline 27 & $02 / 27 / 021056$ & $03 / 01 / 021550$ & 2.21 & 36.8 & 6.1 & 4.2 & $\mathrm{XI}$ \\
\hline 28 & $02 / 27 / 021056$ & $03 / 01 / 021648$ & 2.22 & 38.9 & 5.7 & 4.8 & XI \\
\hline 29 & $02 / 27 / 021056$ & $03 / 02 / 021649$ & 3.22 & 39.9 & 5.0 & 4.6 & XI \\
\hline 30 & $02 / 27 / 021056$ & $03 / 02 / 021649$ & 3.22 & 41.2 & 5.9 & 4.6 & XI \\
\hline 31 & $03 / 10 / 021120$ & $03 / 14 / 021926$ & 4.33 & 13.3 & 9.5 & 4.8 & II \\
\hline 32 & $12 / 10 / 020210$ & $12 / 10 / 021629$ & 0.59 & 3.0 & 10.0 & 4.7 & II \\
\hline 33 & $12 / 29 / 020143$ & $01 / 01 / 030037$ & 2.95 & 47.0 & 7.2 & 4.2 & XVI \\
\hline 34 & $03 / 18 / 031532$ & $03 / 31 / 031413$ & 13.00 & 4.9 & 6.7 & 4.7 & II \\
\hline \multirow[t]{4}{*}{35} & $04 / 03 / 032209$ & $04 / 10 / 031239$ & 6.60 & 21.1 & 12.3 & 4.1 & $\mathrm{X}$ \\
\hline & & $04 / 10 / 031244$ & 6.60 & 22.2 & 15.8 & 3.8 & $X$ \\
\hline & & $04 / 11 / 032153$ & 7.57 & 1.5 & 10.0 & 4.1 & II \\
\hline & & $04 / 12 / 031547$ & 8.73 & 22.4 & 14.5 & 4.3 & IX \\
\hline 36 & $04 / 23 / 030342$ & $04 / 27 / 030238$ & 3.96 & 20.0 & 11.0 & 3.7 & XVII \\
\hline 37 & $05 / 06 / 030515$ & $05 / 1 \mathrm{l} / 030412$ & 4.96 & 22.5 & 14.9 & 4.1 & $X$ \\
\hline
\end{tabular}


Based on the spectra recorded over three years (Figs. 4a, b, c and d), a stressed state at 100 or higher counts/hour and a relaxed state at somewhere between 50 and 100 counts/hour could be recognized on the spectra. The spectra also shown that there is continuous stress applied to this part of the Eurasian plate but there is no significant stress accumulation at these two sites over time. The moderate stress accumulated appears to be released after moderate earthquakes. Two types of spectral variations are recognized. The first type, as exemplified by most part of the spectra, shows a rise of radon counts to a stressed state and then the appearance of an anomalous spike before lowered down to a relaxed state. The second type, as exemplified by the part of spectrum in December 2001, shows a series of consecutive spikes on top of a stressed state and then reduced down to a relaxed state. The spike-like anomaly is defined as above $1 \sigma$ of the counting error of the immediate background. The former may be related to compressive stress with the Philippine Sea plate coming from the southeast. The latter may be related to shear stress with the Philippine Sea plate moving north toward and submerged under

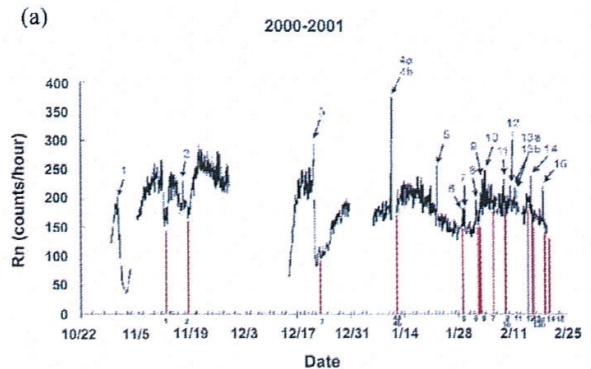

(b)

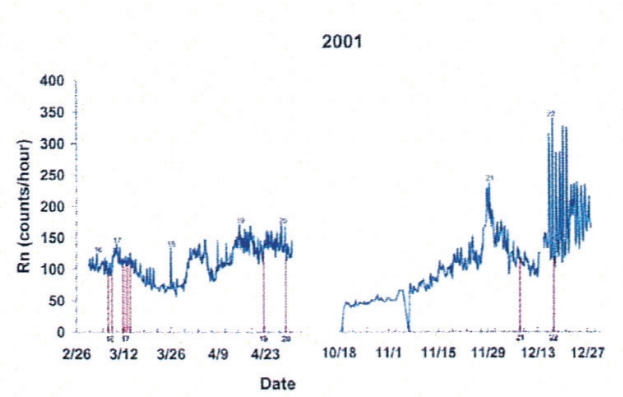

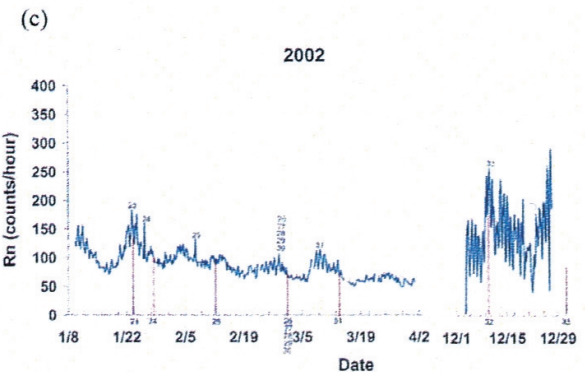

(d)

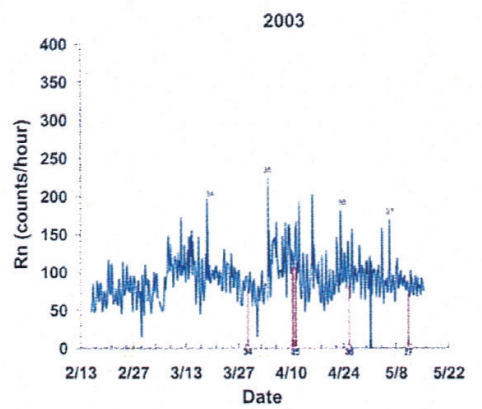

Fig. 4. Radon time series recorded at Taiwan 1. (a) shows the period between the end of October, 2000 and the end of February, 2001; (b) shows the end of February, 2001 to the end of that year; (c) shows radon variation recorded in 2002; and (d) recorded in the first half of 2003. The corresponding time of the onset of the earthquake is shown in a vertical line which intersects the horizontal axis to read off the timing of the earthquake. 
the Ryukyu Trench (Fig. 1). From May to October, varied from year to year, moisture condensation on detector and associated electronics render the counting system unreliable. Spike-like anomaly 18 could not be related to any earthquake occurrence. Radon recording characteristics suggest that it could be related to moisture accumulation also. Efforts are being made at present time to resolve this technical problem.

Monitoring station Taiwan 3 started to function on February 15, 2004 and recorded a twoweek time series. Even the counting rate at Taiwan 3 appears to be lower. There is no real significance for this difference because the counting systems used at these two sites are different. The time series showed the recording of stressed and relaxed state but there is no significant spike-like anomaly recorded during this period.

\section{LABORATORY SIMULATION}

Figure 5a shows a section of the spectrum while temperature and relative humidity are changed artificially by employing a heat lamp. It is clear that by placing the detector inside the PVC housing, radon level is not affected by ambient temperature and relative humidity changes (Fig. 5a). Spike-like radon anomalies are generated when the soil column is wetted from the top (Fig. 5b). When the column is weight stressed, background radon level will increase and spike-like anomalies will appear. Additional stress, however, could only generate additional spike-like peaks but not change the background radon levels. The air pressure in the pores of the column could not sustain very long because the column is confined.

Schubert et al. (2002) showed further how soil gas radon concentration is related to the nature and saturation of fluid in soil pores. With the continuous radon recording, it appears, however, that as the column is weight stressed radon emission rate does increase but the increase appears to be sporadic. That is, the increase in emission is observed as higher and higher spikes (Fig. 5b). It is possible that the increased radon emission at stressed state is actually due to reduction of porosity and the spike-like anomaly is due to sudden purge of radon due to delayed changes of porosity at certain places of the sand column. When we compare these findings to the field observations, the spike-like peak could be the precursors and the reduced level could be the rebuilding period of radon activities in pore spaces immediately before the earthquake. After the purge, radon emission rate is reduced and earthquake could occur before the rebuilding of the radon level in pore spaces.

These facts facilitate our understanding of how precursors are related to earthquakes in time and space. The short half-life of ${ }^{222} \mathrm{Rn}$ provides a time limitation to within a week or two. The stress accumulation in crust is probably limited to that $30 \times 100 \mathrm{~km}$ elliptical domain for a $\mathrm{M}_{\mathrm{L}}=5$ or less. Larger earthquakes could have a much larger stress domain. Most of the earthquakes are shallower than $20 \mathrm{~km}$, so depth has little effect on the extent of the domain. The knowledge obtained in relating spikes to the occurrence of earthquake thus obtained could help us in predicting larger and damaging earthquakes when more stations are established. At this time, the knowledge obtained so far can help us in relating the size of domain to the size of earthquake. In addition, it also helps us in narrowing down the time intervals between the spike and the onset of an earthquake. 
(a)

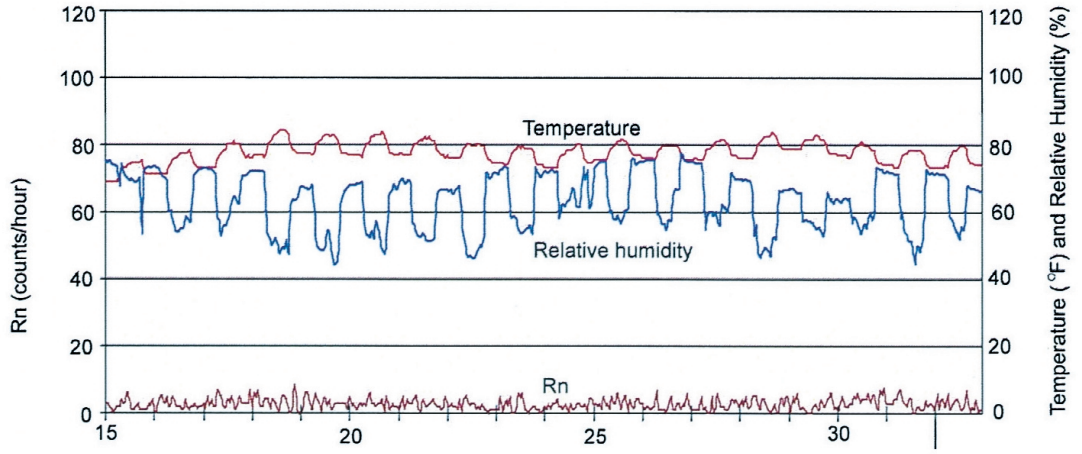

(b)

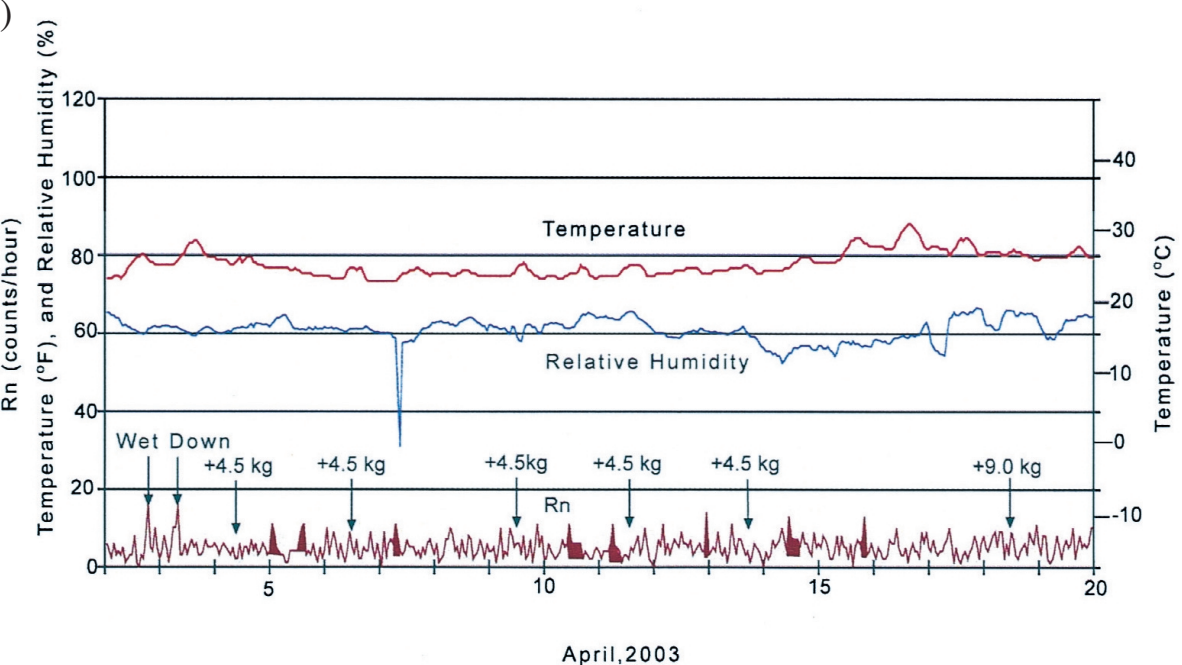

Fig. 5. (a) shows radon variation of Akron 2 as temperature and relative humidity are varied daily. (b) shows radon variation as the column is wetted and weight stressed from the top. Spike-like anomaly appears immediately after wetting but delayed by a day or two (shaded peaks) when weight stressed. The background is somewhat higher than $5 \mathrm{a}$.

\section{CONCLUSION}

From our field observation at Akron 1, it becomes clear that radon spikes could be generated by construction activities such as vibration and pounding activities related to back filling process. In absence of these stress activities, the radon variation over a craton appears to be small and without discernible anomalies.

Continuous observation of spike-like radon anomalies over an area with frequent earthquakes appear to reflect that these anomalies are related to the stress of the terrain. With the 
anomalies occur before perceivable earthquakes in area within roughly a $30 \times 100 \mathrm{~km}$ elliptical area; these anomalies could be used to predict earthquakes. However, we could not determine at this time the magnitude and precise location of the earthquake.

The direction of stress appears to influence radon release pattern. Compressive force first raises the radon level and then produces the spike-like precursors. Earthquake occurrences or the rupture of a fault may have been a random process but the migration of stress appears to be following certain regularity. Therefore, if multiple observing stations are established, more accurate earthquake prediction in terms of magnitude and location could possibly be made.

Acknowledgements The research was supported by the Central Geological Survey and the National Science Council grant (NSC 89-2811-M002-0074) to the co-authors in Taiwan and University of Akron Faculty Research Grant 1541 to the first author. We thank K. W. Wu, D. W. Eshete, A. Gelaye, S. White, J. Smolen and W. Holtz for their helps in different phases of this research and manuscript preparation.

\section{REFERENCES}

Baugues, C. M., 1993: Effects of grain size on radon emanation and migration. MS Thesis, Univ. Akron, $82 \mathrm{pp}$.

Bilham, R., 2005: A flying start, then a slow slip. Science, 308, 1126-1127.

Central Weather Bureau of Taiwan, 2003: Website: http://www.cwb.gov.tw/V4/index.htm

Chyi, L. L., C. Y. Chou, F. T. Yang, and C. H. Chen, 2001: Continuous radon measurements in faults and earthquake precursor pattern recognition. West. Pac. Earth Sci., 1, 227243.

Chyi, L. L., C. Y. Chou, T. F. Yang, and C. H. Chen, 2002a: Automatied radon monitoring of seismicity in a fault zone. Geofisica Internacional, 41, 507-511.

Chyi, L. L., T. J. Quick, T. F. Yang, and C. H. Chen, 2002b: Nature of soil gas radon release and earthquake prediction. GSA Abs. with Prog., 34, 262.

European Space Agency, 2003: Website: http://earth.esa.int/images/INSI/leftframes/ ERS1 22615 ERS2 2942405 459.html

Hauksson, E., and J. G. Goddard, 1981: Radon earthquake precursor studies in Iceland.J. Geophys. Res., 86, 7037-7054.

Jiang, J. H., 2003: The source of natural gases and automatic monitoring results at Chung-lun, Chia-yi. MS Thesis, Nat. Taiwan Univ., 110 pp. (in Chinese)

Lin, C. W., H. C. Chang, S. T. Lu, T. S. Shih, and W. J. Huang, 2000: An introduction to the active faults of Taiwan. Cent. Geol. Surv. Spec. Publ., 13, 122 pp.

Morgounov, V. A., 2001: Relaxation creep model of impending earthquake.Annali di Geofisica, 44, 369-381.

Schubert, M., K. Freyer, H. C. Treutler, and H. Weiss, 2002: Using radon-222 in soil gas as an indicator of subsurface contamination by non-aqueous phase-liquids (NAPLs). Gofisica Internacional, 41, 433-437. 
Sung, Q. C., L. Chen, and Y. C. Chen, 2004: Some observations on the activities of the Chishan Fault. Ti-Chi, 23, 31-40. (in Chinese)

Suppe, J., 1983: Geometry and kinematics of fault-bend folding. Am. J. Sci., 283, 684-721.

Toutain, J. P., and J.C. Baubron, 1998: Gas geochemistry and seismotectonics: a review. Tectonophys., 304, 1-34.

Ulomov, V. I., and B. Z. Mavashev, 1967: O predvesnike sil'nogo tecktonicheskog zemietryarsenia (A precursor of a strong tectonic earthquake). Dokl. Earth Sci. Sect., 176, 9-11.

Walia, V., H. S. Virk, T. F. Yang, S. Mahajan, M. Walia, and B. S. Bajwa, 2005: Earthquake prediction studies using radon as a precursor in N-W Himalayas, India: a case study. Terr. Atmos. Ocean. Sci., 16, 775-804.

Yang, T. F., C. Y. Chou, C. H. Chen, L. L. Chyi, and J. H. Jiang, 2003: Exhalation of radon and its carrier gases in SW Taiwan. Radiat. Meas., 36, 425-429.

Yang, T. F., V. Walia, L. L. Chyi, C. C. Fu, C. H. Chen, T. K. Liu, S. R. Song, C. Y. Lee, and M. Lee, 2005: Variations of soil radon and thoron concentrations in a fault zone and prospective earthquakes in SW Taiwan. Radiat. Meas., 40, 496-502.

Zmazek, B., M. Živčić, L. Todorovski, S. Džeroski, J. Vaupotič, and I. Kobal, 2005: Radon in soil gas: How to identify anomalies caused by earthquakes. Appl. Geochem., 20, 11061119. 